\title{
Is dieting behaviour decreasing in young adolescents?
}

\author{
Claire R Whittle ${ }^{1, *}$, John WG Yarnell ${ }^{2}$, Mike Stevenson ${ }^{2}$, Naomi McCay $^{3}$, \\ Brian P Gaffney ${ }^{4}$, Michael D Shields ${ }^{5}$ and Jayne V Woodside ${ }^{1}$ \\ 'Nutrition and Metabolism Group, Centre for Public Health, Queen's University Belfast, Institute of Clinical \\ Science, Grosvenor Road, Belfast BT12 6BJ, UK: ${ }^{2}$ Epidemiology Research Group, Centre for Public Health, \\ Queen's University Belfast, Belfast, UK: ${ }^{3}$ Public Health Agency, Belfast, UK: ${ }^{4}$ The Surgery, Downpatrick, UK: \\ ${ }^{5}$ Centre for Infection and Immunity, Queen's University Belfast, Belfast, UK
}

Submitted 5 May 2011: Accepted 11 October 2011: First published online 25 November 2011

\begin{abstract}
Objective: To report trends in underweight, overweight and obesity in 12-15-year-old adolescents and examine changes in dieting behaviour, which have been less well documented.

Design: Comparison of two independent representative cross-sectional surveys. Setting: Northern Ireland.

Subjects: Weight and height were objectively measured in 1324 boys and 1160 girls in 1996 and 1274 boys and 1374 girls in 2007. Participants reported whether they were following any particular diet including a self-proposed or prescribed weight-reduction diet.

Results: Overweight and obesity increased in girls from $15 \%$ to $23 \%$ and $2 \%$ to $6 \%$, respectively. Increases were more modest in boys with overweight increasing from $13 \%$ to $18 \%$ and obesity from $3 \%$ to $6 \%$. The proportion of underweight adolescents decreased from $9 \%$ to $6 \%$ in girls and $8 \%$ to $5 \%$ in boys. Evidence of social disparity was observed in girls from a manual socio-economic background, with overweight/obesity prevalence rates increasing from $21 \%$ to $36 \%$ compared with $15 \%$ to $26 \%$ in girls from a non-manual background. Despite these trends fewer adolescents, in particular girls, reported following weight-reduction diets (14\% of overweight/obese girls in 2007 v. $21 \%$ in 1996; 8\% of boys in $2007 v$. $13 \%$ in 1996). Of these girls, the proportion from a manual background following weight-reduction diets decreased from $25 \%$ to $11 \%$.

Conclusions: Overweight and obesity are continuing to increase in adolescents despite government and media awareness strategies. There also appears to be reduced dieting behaviour, despite increasing body weight, particularly in girls from manual socio-economic backgrounds.
\end{abstract}

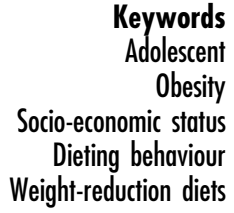

Keywords Adolescent Obesity Dio-economic status Weight-reduction diets
Childhood obesity has escalated worldwide over the past two decades ${ }^{(1-3)}$, with obesity complications, previously thought of as adult conditions, now affecting children ${ }^{(4-7)}$. In addition excess body weight in childhood and particularly in adolescence has the tendency to track into adulthood $^{(8,9)}$. Thus, from a public health perspective, this is an important time to monitor weight trends.

Ireland is no exception to the obesity epidemic, with $25 \%$ of young children ${ }^{(10,11)}$ and adolescents ${ }^{(11)}$ overweight and obese compared with $19 \%$ in Great Britain ${ }^{(12)}$. Alarmingly, an international survey identified adolescents from Ireland among the most obese in the world ${ }^{(13)}$. Epidemiological evidence from Northern Ireland (NI) is sparse, with $25 \%$ of 4-16-year-olds overweight or obese in $2002^{(14)}$; similar to that reported in the Republic of Ireland in $1998^{(13)}$. Trend data from the Young Hearts Project reported overall increases in height and weight in 12-15-year-olds between 1990 and 2000, with overweight and obesity increasing from $15 \cdot 0 \%$ to $19 \cdot 6 \%{ }^{(15)}$. However no trend data from NI have been published since. It would be of interest to see if recent trend data replicate those in England showing marked increases in obese young people between 1995 and 2005, but a plateau or even a decrease towards $2007^{(16)}$. Moreover, those from lower socio-economic circumstances appear to be at greater risk $^{(12,16,17)}$, particularly girls ${ }^{(17)}$. Future projections highlight this socio-economic divide to worsen in England ${ }^{(16)}$ but the magnitude of this gap within NI adolescents is unknown.

In the recent years of the 'obesity epidemic', research examining trends of underweight among children has been neglected. In Scotland $3.3 \%$ of pre-school children were identified as underweight, which was related to social deprivation $^{(18)}$, while trend data in 9-10-year-olds from 1998 to 2006 observed a decline ${ }^{(19)}$. Few data are available on the 
prevalence of underweight adolescents and given the media emphasis of body image ${ }^{(20)}$ this is an important time to examine both ends of the body mass spectrum.

It would also be of interest to examine whether the dieting behaviour of adolescents has changed over time. An association between overweight children and an increased risk of disordered eating symptoms including weight concerns, dieting and other unhealthy weightcontrol methods has been established ${ }^{(21)}$. There is the perception in the Western world that thinness is the ideal body shape, particularly for females. Therefore, investigating whether adherence to weight-reduction diets has increased in parallel with increasing obesity would be of interest, particularly as disordered eating patterns can predict future weight gain ${ }^{(22)}$.

Earlier cross-sectional data from our group collected in 1996 from NI adolescents aged 12-15 years observed that $16 \%$ were overweight and obese and low levels of concern or awareness manifested as attempts to modify diet ${ }^{(23)}$. By repeating this representative cross-sectional study in the same age group, we had the opportunity to examine more recent trends. In the present paper we investigate 11-year trends in underweight, overweight and obesity in 12-15-year-old adolescents in NI and examine changes in dieting behaviour.

\section{Subjects and methods}

\section{Survey and sample population}

These surveys were conducted using data from the International Study of Asthma and Allergies (ISAAC), which is a series of worldwide repeat cross-sectional studies in schoolchildren. Investigations in NI have been conducted in 12-15year-olds, following ethical approval granted by the Queen's University Research Ethics Committee in 1996 and the Office of Research Ethics Committees Northern Ireland in 2007. The sampling procedure for each survey aimed to obtain a random sample of schoolchildren, stratified by management type and approximating to religious affiliation and geographical area. The five Education and Library Boards in NI were contacted and lists of secondary and grammar schools were obtained. Letters detailing the study design and objectives were sent to a predefined number of school principals within each board and management sector; if they agreed to participate in the study, consent was obtained on a class basis unless a parent or child opted out. If the principal was unable to accommodate the researchers, the school was replaced at random by another in the same stratum.

\section{Anthropometry and questionnaire data}

Previous work conducted by our group investigated the cross-sectional data from the 1996 cohort $^{(23)}$. Briefly, heights and weights were measured by two trained researchers while participants were wearing lightweight clothing and no shoes, using equipment which was available in each school and after calibration with standard measures. Questionnaires were completed by the selected participants under classroom conditions. The further data collection in 2007 has now provided the opportunity to examine trends in overweight and obesity in NI adolescents over the past 11 years. Data collection was carried out in the same manner as before, only this time using the same calibrated equipment for every school. Both surveys incorporated questions to assess dieting behaviour. Two questions were of relevance to the present paper. First, the participants were asked the occupation of their father and/or mother, which was categorised into manual or non-manual socio-economic status (SES) according to the Registrar General's Classification $^{(24)}$. The participant's SES was based on the highest socio-economic occupation within the household. Second the participants were asked if they were following any special diet and, if so, they were asked to select one of the following: (i) a weight-reducing diet devised by yourself or a parent; (ii) a weight-reducing diet proposed by a dietitian or doctor; (iii) a diet prescribed for a medical reason such as diabetes or food allergy; (iv) a vegetarian diet; or (v) other (please specify).

\section{Definition of underweight, overweight and obesity} The International Obesity Taskforce (IOTF) age (to nearest 6 months) and sex-specific BMI thresholds for defining underweight (thinness), overweight and obesity classification between 2- and 18-year-olds were used ${ }^{(25,26)}$.

\section{Statistical analysis}

Statistical tests were carried out using the SPSS statistical software package version $17 \cdot 0$ (SPSS UK Ltd, Chertsey, UK). Differences in the proportions of underweight, overweight and obese children and those on specific diets between the two surveys were analysed using $\chi^{2}$ tests and $\chi^{2}$ tests for trend as appropriate. The mean and standard deviation were calculated for height, weight and BMI, in addition to BMI across specific diet groups, between the surveys. Differences were then assessed using independent-sample $t$ tests for boys and girls adjusting for age. Confidence intervals for small proportions (i.e. those on weight-reducing/medical diets within each of the weight categories) were calculated using Wilson's Procedure with continuity correction ${ }^{(27)}$. Due to the number of significance tests applied and to reduce the number of spurious significant results that could ensue, we applied a significance level of $0 \cdot 01$ rather than the customary $0 \cdot 05$.

\section{Results}

\section{Response rate}

A total sample of 2484 adolescents ( $53 \%$ male) completed the survey in 1996 from twenty-six schools across NI between the months of April to June. The overall 
response rate was high with less than $0.5 \%$ of parents refusing consent to their child's participation in the study. Approximately 10\% (258 adolescents) of those adolescents initially selected for participation in the survey did not complete the questionnaire due to absenteeism at the time of researchers visiting the schools. The 2007 survey consisted of 2647 adolescents (48\% male) from twentyfour schools across the same geographical area between the months of May to November. Approximately $1 \%$ of parents refused their child's participation in the study, and 14\% (427 adolescents) were absent on the day of survey completion. There was a small trend in socio-economic distribution of families from semi/unskilled in 1996 towards professional in 2007 reflecting a societal change over the 11-year period, with a small increase in single-parent families.

\section{Prevalence of underweight, overweight and obesity}

The prevalence of overweight and obesity increased significantly over the decade between the two surveys (Table 1), with rates of overweight and obesity increasing from $13 \cdot 6 \%$ to $20 \cdot 4 \%$ and from $3 \cdot 0 \%$ to $6 \cdot 2 \%$ respectively, in contrast to a decrease from $8 \cdot 4 \%$ to $5 \cdot 0 \%$ in prevalence of underweight in all adolescents $(P<0 \cdot 001)$. Overall the largest trend towards overweight and obesity was seen in girls, with the prevalence of obesity increasing from $2 \cdot 4 \%$ to $6 \cdot 4 \%$ and overweight from $14 \cdot 5 \%$ to $22 \cdot 8 \%$. As with girls, a significant trend towards increasing overweight and obesity was also observed in boys, increasing from $12 \cdot 8 \%$ to $17 \cdot 9 \%$ and from $3 \cdot 4 \%$ to $6 \cdot 0 \%$ respectively. Table 2 shows that mean weight and BMI, but not height, increased significantly (both $P \leq 0 \cdot 001$ ) in both boys and girls between the two surveys. These analyses were adjusted for age, as there was a 3-month mean age difference between the two cohorts. A further adjustment for SES did not significantly alter the results.

\section{Dieting behaviour}

Table 3 highlights an overall reduced level of dietary concern in 2007 compared with 1996, particularly in girls; 19.5\% of girls in 1996 were following some form of special diet compared with $10 \cdot 7 \%$ in 2007 . The percentage of girls following a self-proposed weight-reduction diet decreased from $10 \cdot 7 \%$ to $5 \cdot 8 \%$ although this remained stable for boys $(3 \cdot 6 \%$ to $3 \cdot 2 \%)$. The reduction in girls following a selfproposed weight-reducing diet occurred even though there was an increase in mean BMI over the same period. The proportion of adolescents following a prescribed weightreduction or medical diet (1996, 2.0\% and 1.4\%; 2007, 0.9\% and $0.9 \%$, girls and boys respectively) remained relatively

Table 1 Eleven-year trends in underweight, overweight and obesity based on BMI in Northern Ireland adolescents aged 12-15 years: data from the International Study of Asthma and Allergies (ISAAC) ${ }^{*}$

\begin{tabular}{|c|c|c|c|c|c|c|c|c|c|}
\hline \multirow[b]{2}{*}{ Survey } & \multicolumn{2}{|c|}{ Underweight } & \multicolumn{2}{|c|}{ Normal weight } & \multicolumn{2}{|c|}{ Overweight } & \multicolumn{2}{|c|}{ Obese } & \multirow[b]{2}{*}{$P$ value } \\
\hline & $n$ & $\%$ & $n$ & $\%$ & $n$ & $\%$ & $n$ & $\%$ & \\
\hline \multicolumn{10}{|l|}{ All adolescents } \\
\hline ISAAC 1996 & 193 & $8 \cdot 4$ & 1719 & $75 \cdot 0$ & 311 & $13 \cdot 6$ & 68 & $3 \cdot 0$ & \multirow[t]{2}{*}{$<0.001$} \\
\hline ISAAC 2007 & 132 & $5 \cdot 0$ & 1792 & $68 \cdot 3$ & 536 & $20 \cdot 4$ & 162 & $6 \cdot 2$ & \\
\hline \multicolumn{10}{|l|}{ Boys } \\
\hline ISAAC 1996 & 95 & $7 \cdot 7$ & 934 & $76 \cdot 1$ & 157 & $12 \cdot 8$ & 42 & $3 \cdot 4$ & \multirow[t]{2}{*}{$<0.001$} \\
\hline ISAAC 2007 & 58 & $4 \cdot 6$ & 908 & $71 \cdot 6$ & 227 & $17 \cdot 9$ & 76 & $6 \cdot 0$ & \\
\hline \multicolumn{10}{|l|}{ Girls } \\
\hline ISAAC 1996 & 98 & $9 \cdot 2$ & 785 & $73 \cdot 8$ & 154 & $14 \cdot 5$ & 26 & $2 \cdot 4$ & \multirow[t]{2}{*}{$<0.001$} \\
\hline ISAAC 2007 & 74 & $5 \cdot 5$ & 884 & $65 \cdot 3$ & 309 & $22 \cdot 8$ & 86 & $6 \cdot 4$ & \\
\hline
\end{tabular}

Differences in the proportions of underweight, normal weight, overweight and obese adolescents in each cohort were analysed using the $\chi^{2}$ test for trend.

*Data missing for $n 193$ from ISAAC 1996 and $n 26$ from ISAAC 2007.

Table 2 Eleven-year trends in height, weight and BMI in Northern Ireland adolescents aged 12-15 years following age adjustment: data from the International Study of Asthma and Allergies (ISAAC)

\begin{tabular}{|c|c|c|c|c|c|c|c|}
\hline & \multicolumn{2}{|c|}{ ISAAC 1996} & \multicolumn{2}{|c|}{ ISAAC 2007} & \multicolumn{2}{|c|}{ Difference in means } & \multirow[b]{2}{*}{$P$ value } \\
\hline & Mean & SE & Mean & SE & Mean & $95 \% \mathrm{Cl}$ & \\
\hline \multicolumn{8}{|c|}{ Height $(\mathrm{cm})$} \\
\hline Boys & $161 \cdot 9$ & $0 \cdot 0$ & $162 \cdot 4$ & 0.2 & $0 \cdot 6$ & $-0 \cdot 1,1 \cdot 2$ & $0 \cdot 120$ \\
\hline Girls & $159 \cdot 2$ & 0.2 & $159 \cdot 6$ & 0.2 & $0 \cdot 4$ & $-0.1,0.9$ & $0 \cdot 150$ \\
\hline \multicolumn{8}{|c|}{ Weight (kg) } \\
\hline Boys & $52 \cdot 1$ & 0.3 & $54 \cdot 4$ & 0.3 & $2 \cdot 3$ & $1 \cdot 3,3 \cdot 2$ & $<0.001$ \\
\hline Girls & $51 \cdot 3$ & 0.3 & $54 \cdot 8$ & 0.3 & $3 \cdot 4$ & $2 \cdot 5,4 \cdot 3$ & $<0.001$ \\
\hline \multicolumn{8}{|c|}{ BMI $\left(\mathrm{kg} / \mathrm{m}^{2}\right)$} \\
\hline Boys & $19 \cdot 8$ & $0 \cdot 1$ & $20 \cdot 4$ & $0 \cdot 1$ & $0 \cdot 7$ & $0.4,0.9$ & $<0.001$ \\
\hline Girls & $20 \cdot 2$ & $0 \cdot 1$ & $21 \cdot 4$ & $0 \cdot 1$ & $1 \cdot 2$ & $0.9,1.5$ & $<0.001$ \\
\hline
\end{tabular}

Differences between the two cohorts were analysed using one-way analysis of covariance controlling for age, significant when $P \leq 0 \cdot 01$. 
Table 3 Number, percentage and BMI of adolescents aged 12-15 years on particular diets in Northern Ireland: data from the International Study of Asthma and Allergies (ISAAC)

\begin{tabular}{|c|c|c|c|c|c|c|c|c|c|c|}
\hline & \multicolumn{5}{|c|}{ Boys } & \multicolumn{5}{|c|}{ Girls } \\
\hline & \multicolumn{2}{|c|}{ BMI $\left(\mathrm{kg} / \mathrm{m}^{2}\right)$} & \multirow[b]{2}{*}{$n^{*}$} & \multirow[b]{2}{*}{$\%$} & \multirow[b]{2}{*}{$P$ value } & \multicolumn{2}{|c|}{ BMI $\left(\mathrm{kg} / \mathrm{m}^{2}\right)$} & \multirow[b]{2}{*}{$n^{*}$} & \multirow[b]{2}{*}{$\%$} & \multirow[b]{2}{*}{$P$ value } \\
\hline & Mean & SD & & & & Mean & SD & & & \\
\hline \multicolumn{11}{|l|}{ No special diet } \\
\hline ISAAC 1996 & $19 \cdot 7$ & $3 \cdot 2$ & 1190 & $94 \cdot 0$ & \multirow[t]{2}{*}{0.942} & $20 \cdot 1$ & $3 \cdot 1$ & 922 & $80 \cdot 5$ & \multirow[t]{2}{*}{0.078} \\
\hline ISAAC 2007 & $20 \cdot 3$ & $3 \cdot 6$ & 1186 & $93 \cdot 6$ & & $21 \cdot 2$ & $3 \cdot 7$ & 1218 & $89 \cdot 3$ & \\
\hline \multicolumn{11}{|c|}{ Weight-reducing proposed by self } \\
\hline ISAAC 1996 & $23 \cdot 0$ & $4 \cdot 1$ & 45 & $3 \cdot 6$ & \multirow[t]{2}{*}{0.591} & $21 \cdot 6$ & $3 \cdot 5$ & 123 & $10 \cdot 7$ & \multirow[t]{2}{*}{$\leq 0.001$} \\
\hline ISAAC 2007 & $23 \cdot 4$ & $4 \cdot 2$ & 40 & $3 \cdot 2$ & & $24 \cdot 1$ & $4 \cdot 4$ & 79 & $5 \cdot 8$ & \\
\hline \multicolumn{11}{|c|}{ Prescribed weight-reducing or medical diett } \\
\hline ISAAC 1996 & $19 \cdot 8$ & $3 \cdot 8$ & 12 & 0.9 & \multirow{2}{*}{0.834} & $22 \cdot 5$ & $5 \cdot 6$ & 23 & $2 \cdot 0$ & \multirow[t]{2}{*}{0.240} \\
\hline ISAAC 2007 & $20 \cdot 1$ & $2 \cdot 4$ & 11 & 0.9 & & $22 \cdot 2$ & $3 \cdot 0$ & 19 & $1 \cdot 4$ & \\
\hline \multicolumn{11}{|l|}{ Vegetarian } \\
\hline ISAAC 1996 & $19 \cdot 1$ & $1 \cdot 7$ & 9 & $0 \cdot 7$ & \multirow[t]{2}{*}{$0 \cdot 167$} & $20 \cdot 3$ & 3.9 & 56 & 4.9 & \multirow[t]{2}{*}{$\leq 0.001$} \\
\hline ISAAC 2007 & $21 \cdot 2$ & $5 \cdot 8$ & 4 & $0 \cdot 3$ & & $22 \cdot 2$ & $4 \cdot 5$ & 23 & $1 \cdot 7$ & \\
\hline \multicolumn{11}{|l|}{ Other } \\
\hline ISAAC 1996 & $21 \cdot 9$ & $3 \cdot 0$ & 10 & $0 \cdot 8$ & \multirow[t]{2}{*}{0.008} & $18 \cdot 8$ & $3 \cdot 2$ & 22 & $1 \cdot 9$ & \multirow[t]{2}{*}{0.455} \\
\hline ISAAC 2007 & $20 \cdot 4$ & $4 \cdot 4$ & 26 & $2 \cdot 1$ & & $21 \cdot 7$ & $4 \cdot 1$ & 25 & $1 \cdot 8$ & \\
\hline \multicolumn{11}{|l|}{ Total } \\
\hline ISAAC 1996 & $19 \cdot 8$ & $3 \cdot 3$ & 1266 & 100 & & $20 \cdot 3$ & $3 \cdot 3$ & 1146 & 100 & \\
\hline ISAAC 2007 & $20 \cdot 4$ & $3 \cdot 7$ & 1267 & 100 & & $21 \cdot 4$ & 3.9 & 1364 & 100 & \\
\hline
\end{tabular}

*Data unavailable for eighty-nine adolescents.

tPrescribed weight-reducing (1996, $n 2$ and $n 5 ; 2007, n 1$ and $n 3$, boys and girls respectively) or medical diet (1996, $n 9$ and $n 16 ; 2007, n 9$ and $n 16$ boys and girls respectively). Differences between the number of children for specific diet category in each cohort analysed using the $\chi^{2}$ test, significant when $P \leq 0 \cdot 01$.

Table 4 Comparison of number and percentage of Northern Ireland adolescents aged 12-15 years on weight-reduction diets (selfproposed or prescribed) over an 11-year period: data from the International Study of Asthma and Allergies (ISAAC)

\begin{tabular}{|c|c|c|c|c|c|c|c|c|c|c|}
\hline \multirow[b]{3}{*}{ Cohort } & \multicolumn{5}{|c|}{ Overweight and obese } & \multicolumn{5}{|c|}{ Normal weight and underweight } \\
\hline & \multirow[b]{2}{*}{$n$} & \multicolumn{2}{|c|}{ On diet } & \multirow[b]{2}{*}{$\%$ Difference } & \multirow[b]{2}{*}{$95 \% \mathrm{Cl}$} & \multirow[b]{2}{*}{$n$} & \multicolumn{2}{|c|}{ On diet } & \multirow[b]{2}{*}{$\%$ Difference } & \multirow[b]{2}{*}{$95 \% \mathrm{Cl}$} \\
\hline & & $n$ & $\%$ & & & & $n$ & $\%$ & & \\
\hline \multicolumn{11}{|l|}{ Boys } \\
\hline $\begin{array}{l}\text { ISAAC } 1996 \\
\text { ISAAC } 2007\end{array}$ & $\begin{array}{l}189 \\
302\end{array}$ & $\begin{array}{l}24 \\
21\end{array}$ & $\begin{array}{r}12 \cdot 7 \\
7 \cdot 0\end{array}$ & $-5 \cdot 7$ & $-12 \cdot 1,-0 \cdot 2$ & $\begin{array}{l}986 \\
960\end{array}$ & $\begin{array}{l}18 \\
20\end{array}$ & $\begin{array}{l}1 \cdot 8 \\
2 \cdot 1\end{array}$ & -0.3 & $-1 \cdot 6,1 \cdot 1$ \\
\hline \multicolumn{11}{|l|}{ Girls } \\
\hline $\begin{array}{l}\text { ISAAC } 1996 \\
\text { ISAAC } 2007\end{array}$ & $\begin{array}{l}178 \\
395\end{array}$ & $\begin{array}{l}33 \\
51\end{array}$ & $\begin{array}{l}18 \cdot 5 \\
12 \cdot 9\end{array}$ & $-5 \cdot 6$ & $-13 \cdot 0,0 \cdot 9$ & $\begin{array}{l}874 \\
949\end{array}$ & $\begin{array}{l}86 \\
29\end{array}$ & $\begin{array}{l}9 \cdot 8 \\
3 \cdot 1\end{array}$ & $-6 \cdot 8$ & $-9 \cdot 2,-4 \cdot 5$ \\
\hline \multicolumn{11}{|l|}{ All adolescents } \\
\hline $\begin{array}{l}\text { ISAAC } 1996 \\
\text { ISAAC } 2007\end{array}$ & $\begin{array}{l}367 \\
697\end{array}$ & $\begin{array}{l}57 \\
72\end{array}$ & $\begin{array}{l}15 \cdot 5 \\
10 \cdot 3\end{array}$ & $-5 \cdot 2$ & $-9 \cdot 9,-0.9$ & $\begin{array}{l}1860 \\
1909\end{array}$ & $\begin{array}{r}104 \\
49\end{array}$ & $\begin{array}{l}5 \cdot 6 \\
2 \cdot 6\end{array}$ & $-3 \cdot 0$ & $-4 \cdot 4,-1 \cdot 7$ \\
\hline
\end{tabular}

$\mathrm{Cl}$ calculated using Wilson's Procedure with continuity correction ${ }^{(27)}$.

stable despite the overall increasing prevalence of overweight and obesity; all those who were on prescribed weight-reducing diets had a BMI $>25 \mathrm{~kg} / \mathrm{m}^{2}$. The percentage following a vegetarian diet decreased threefold in girls and twofold in boys over the 11-year period.

Examining those adolescents who were following a self-proposed or prescribed weight-reduction diet by BMI category (Table 4) revealed a smaller proportion of overweight/obese adolescents following weight-reduction diets in 2007 compared with 1996. Overweight and obese boys following these particular diets decreased from $12 \cdot 7 \%$ to $7 \cdot 0 \%$ and girls from $18 \cdot 5 \%$ to $12 \cdot 9 \%$. Also we hypothesised that more girls in the normal weight/ underweight category would be following self-proposed weight-reduction diets in 2007 due to media-generated peer pressure; however this was not the case, and only
$3 \cdot 1 \%$ of these girls were following weight-reduction diets in 2007 compared with $9 \cdot 8 \%$ in the previous survey.

\section{Change in weight and dieting behaviour by socio-economic status}

Figure 1 indicates that the relative risk of being overweight and obese as a proportion of all young people generally increased with a manual socio-economic background, being female and being from the later cohort. Boys showed little difference across the socio-economic groups, although they did show significant increases over time. Girls, whether from a manual or non-manual background, showed the greatest increased relative risk over time. On investigating the proportion of overweight/obese adolescents following weight-reduction diets (either self-proposed or prescribed), girls from a manual socio-economic background had the 

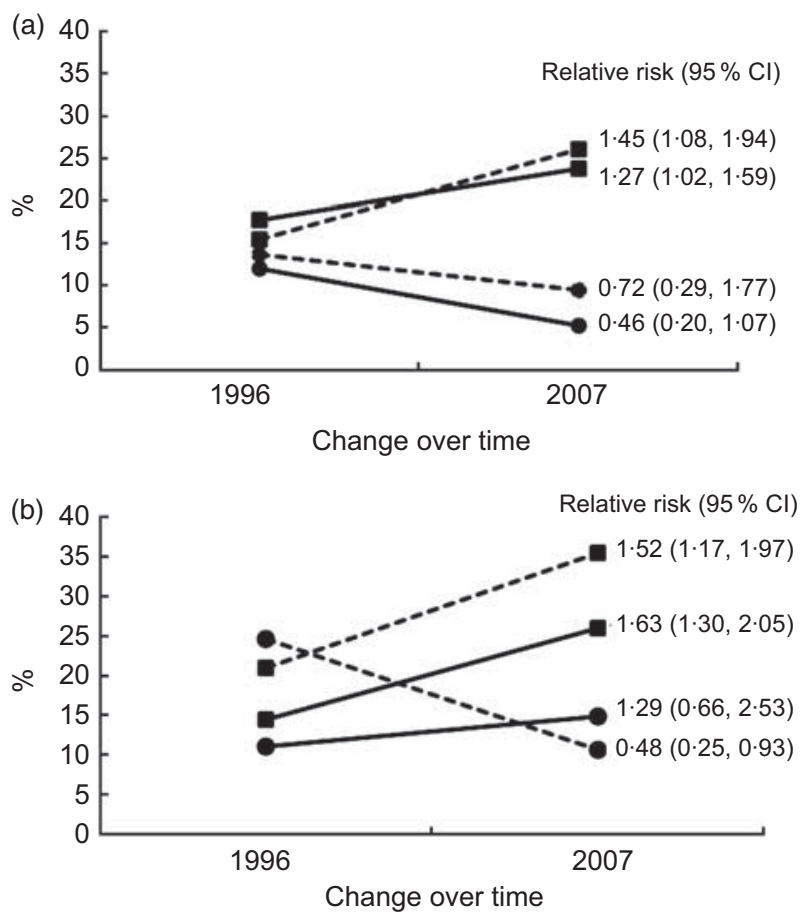

Fig. 1 Evidence of social disparities over time in dieting behaviour among overweight and obese (OW/OB) boys (a) and girls (b) aged 12-15 years in Northern Ireland: -- -- , $\%$ OW/OB from manual socio-economic status (SES); - - $\%$ OW/OB from non-manual SES; - - - --, \% OW/OB on diet from manual SES; - — , \% OW/OB on diet from non-manual SES. Data from the International Study of Asthma and Allergies (ISAAC)

greatest decrease over time from $24 \cdot 6 \%$ to $10 \cdot 6 \%$ (relative risk $0 \cdot 48,95 \%$ CI $0 \cdot 25,0 \cdot 93$ ). Proportionally smaller decreases were observed in boys from both manual and non-manual backgrounds whereas a slight increase was noted in girls from a non-manual background.

\section{Discussion}

The current study observed marked increases in the prevalence of overweight and obesity over an 11-year period in 12-15-year-old adolescents from NI. Approximately $30 \%$ of the girls surveyed were classified as overweight or obese using international definitions ${ }^{(26)}$ with the prevalence of obesity increasing threefold. Increases over time were more modest for boys; however $25 \%$ were still classified as overweight or obese. These increases occurred predominantly in body weight since increases in height were smaller and non-significant. It was hypothesised that, along with increases in overweight and obesity, the prevalence of underweight adolescents, particularly girls, would increase as a result of increased awareness of body image due to a media focus on fashion and celebrities. On the contrary, there appeared to be a reduced dietary concern, particularly in girls, as less reported being on a self-prescribed or medical weight-reduction diet, despite the trend for increasing BMI. Of particular concern was the evidence of social disparity between girls from manual and non-manual socio-economic backgrounds. Even though there was an upward trend in overweight/obesity in both groups, the proportion of girls from a manual background actually following weight-reduction diets decreased from $25 \%$ to $11 \%$ compared with a small increase in the non-manual girls.

This research provides the most recent estimates of underweight, overweight and obesity in adolescents of this age group in NI. Approximately $25 \%$ of boys, but only $21 \%$ of girls aged $12-15$ years were overweight or obese in data collected in NI from the North South Ireland Survey ${ }^{(14)}$ conducted in 2001. However, it must be noted that the NI subset for that previous survey was smaller ( $n$ 860) and with a lower response rate at $53 \%{ }^{(14)}$ than the current study. In agreement with our data, significant increased trends in the number of adolescents who were overweight and obese over a 10-year period in NI has previously been reported $^{(15)}$. However the Young Hearts Project also reported significant increases in height over time $^{(15)}$. The Young Hearts data ${ }^{(15)}$ estimated increases in overweight and obesity from $15 \cdot 0 \%$ to $19 \cdot 6 \%$ from 1990 to 2000 whereas we observed a larger increase from $16 \cdot 6 \%$ to $26 \cdot 6 \%$ from 1996 to 2007 , suggesting that the obesity epidemic is still a major and increasing public health issue in adolescents from NI. However some recent research ${ }^{(16,28)}$ has shown that the trend in childhood obesity may have reached a plateau. In both of these studies ${ }^{(16,28)}$, trend data were collected at more time points than in the current survey. Therefore, it is possible that the prevalence rates in NI adolescents increased greatly over the earlier years and have slowed down or reached a plateau more recently.

A novel aspect of the present research was the collection of information on adolescents' dieting behaviour. A recent qualitative investigation from the Republic of Ireland on adolescent girls observed a high level of body dissatisfaction significantly influenced by media celebrities, together with a high prevalence of dieting ${ }^{(29)}$. Given these perceptions we had hypothesised that more girls, particularly in the normal weight and underweight category, would be following weight-reduction diets, as observed in a study of Dublin schoolgirls ${ }^{(30)}$. However this was not the case and fewer girls were following selfproposed weight-reduction diets, despite significant increases in BMI over time, particularly those girls from a manual socio-economic background. This widening of social disparities in dietary awareness in adolescents from NI mirrors that observed in England ${ }^{(16,17)}$ and suggests that the current obesity strategies are either ineffective for those from a manual background, particularly girls, or are more actively followed by those from a higher socioeconomic background. A potential cause for this widening in social disparities in girls may be that lower-SES children tend to spend more time in screen-based 
sedentary behaviours compared with those from higher SES. However, overall, boys (regardless of SES) also tend to spend more time in sports participation than girls, suggesting that lower-SES boys find time for sedentary behaviours and physical activity ${ }^{(31)}$.

In Great Britain changing perceptions of body weight in adults have also been noted ${ }^{(32)}$, with a considerable proportion of the population, especially men, failing to recognise themselves or their children as overweight $^{(33-35)}$. Population surveys conducted in 1999 and 2007 have highlighted a significant decline in the proportion of individuals correctly identifying themselves as overweight despite the fact that the obesity epidemic is rarely out of the media ${ }^{(32)}$. Possible reasons for this may be that we are continually exposed to images of severe obesity from the media, portraying that extreme adiposity is required to meet medical criteria for overweight, or that excess weight is now so familiar in the general population that we have a reduced awareness of what excess weight actually is ${ }^{(32)}$. In addition, recent evidence has shown that the proportion of primary care practitioners addressing the issue of overweight with their patients is inadequate ${ }^{(36)}$. Although the present study did not directly measure adolescent awareness or concern of being overweight, it seems likely that perception of body size over time has reduced in this population, seeing as the prevalence of overweight/ obese adolescents has increased while those actively following weight-reduction diets has decreased.

The high response rate from the 1996 and 2007 surveys, together with the careful selection of a representative sample of adolescents from all school types, are strengths of the present research and provide confidence that the prevalence rates are reliable. On the other hand, the cross-sectional nature of these surveys cannot identify any causal factors for increasing overweight and obesity; but whatever the reasons, the condition is continuing to rise in adolescents from NI. It is well documented that obesity in childhood and adolescence tends to track into adulthood $^{(8,9)}$ along with adverse dietary and physical behaviours known to promote obesity ${ }^{(37-39)}$. Obesity and accompanying dietary and physical behaviours are predictors of adult morbidity and mortality, in the form of CVD and diabetes which are major public health burdens ${ }^{(5,6,40)}$. In the present research we chose to use the IOTF classification of overweight and obesity in children. The use of international cut-off points of BMI is controversial; some have expressed their concern that the IOTF classification underestimates the magnitude of the problem $^{(41)}$, while others have stressed that the use of national standards inflates the problem in children, and a single definition needs to be consistently applied ${ }^{(42)}$. Nevertheless, these international cut-off points are increasingly being used in national and international studies $^{(10,12,15,23,43-45)}$, and we used these definitions for the sake of consistency with our previous report and comparability with other studies.

\section{Conclusions}

The findings of the present study highlight that current government obesity strategies are not adequate and more focused interventions are warranted. The differing trends in overweight/obesity and dietary behaviour by gender and socio-economic background from the present research suggest that the development of separate strategies may be necessary for these factors. Finally, health professionals need to take greater action in the prevention and treatment of childhood obesity, as no significant increases in prescribed weight-reduction diets over time were observed, despite dramatic increases in childhood overweight and obesity.

\section{Acknowledgements}

This work was supported by funds from the Health Promotion Agency for Northern Ireland and the Child Health \& Welfare Recognised Research Grouping, Research \& Development Office, DHSS Northern Ireland. The authors declare that they have no conflicts of interest. C.R.W. analysed the data and drafted the paper; J.V.W., N.M., and M.D.S. helped draft the paper; B.P.G. helped plan the study with J.W.G.Y., who was Principal Investigator for the study. M.S. advised on the sample selection, assisted with the random selection of schools and advised and assisted with the statistical analysis. The authors thank the participating schools, head teachers, parents and children included in the study and acknowledge the meticulous assistance of fieldworkers Ruth Leathem and Pauline Nolan and the technical assistance of Laura Stevenson.

\section{References}

1. Ogden CL, Carroll MD, Curtin LR et al. (2006) Prevalence of overweight and obesity in the United States, 1999-2004. JAMA 295, 1549-1555.

2. Ogden CL, Flegal KM, Carroll MD et al. (2002) Prevalence and trends in overweight among US children and adolescents, 1999-2000. JAMA 288, 1728-1732.

3. Wang Y \& Lobstein T (2006) Worldwide trends in childhood overweight and obesity. Int J Pediatr Obes 1, 11-25.

4. World Health Organization (2000) Obesity: Preventing and Managing the Global Epidemic. Report of a WHO Consultation. WHO Technical Report Series no. 894. Geneva: WHO.

5. Must A \& Strauss RS (1999) Risks and consequences of childhood and adolescent obesity. Int J Obes Relat Metab Disord 23, Suppl. 2, S2-S11.

6. Dietz WH (1998) Health consequences of obesity in youth: childhood predictors of adult disease. Pediatrics 101, 518-525.

7. Lobstein T, Baur L, Uauy R et al. (2004) Obesity in children and young people: a crisis in public health. Obes Rev $\mathbf{5}$, Suppl. 1, 4-104.

8. Whitaker RC, Wright JA, Pepe MS et al. (1997) Predicting obesity in young adulthood from childhood and parental obesity. N Engl J Med 337, 869-873.

9. Power C, Lake JK \& Cole TJ (1997) Body mass index and height from childhood to adulthood in the 1958 British born cohort. Am J Clin Nutr 66, 1094-1101. 
10. McMaster C, Cullen L \& Raymond N (2005) Overweight and obesity in Irish primary schools: retrospective cohort study. Child Care Health Dev 31, 499-506.

11. O'Neill JL, McCarthy SN, Burke SJ et al. (2007) Prevalence of overweight and obesity in Irish school children, using four different definitions. Eur J Clin Nutr 61, 743-751.

12. Jebb SA, Rennie KL \& Cole TJ (2004) Prevalence of overweight and obesity among young people in Great Britain. Public Health Nutr 7, 461-465.

13. Lissau I, Overpeck MD, Ruan WJ et al. (2004) Body mass index and overweight in adolescents in 13 European countries, Israel, and the United States. Arch Pediatr Adolesc Med 158, 27-33.

14. Whelton H, Harrington J, Crowley E et al. (2007) Prevalence of overweight and obesity on the island of Ireland: results from the North South Survey of Children's Height, Weight and Body Mass Index, 2002. BMC Public Health 7, 187.

15. Watkins DC, Murray LJ, McCarron P et al. (2005) Ten-year trends for fatness in Northern Irish adolescents: the Young Hearts Projects - repeat cross-sectional study. Int $J$ Obes (Lond) 29, 579-585.

16. Stamatakis E, Zaninotto P, Falaschetti E et al. (2010) Time trends in childhood and adolescent obesity in England from 1995 to 2007 and projections of prevalence to 2015 . J Epidemiol Community Health 64, 167-174.

17. Howe LD, Galobardes B, Sattar N et al. (2010) Are there socioeconomic inequalities in cardiovascular risk factors in childhood, and are they mediated by adiposity? Findings from a prospective cohort study. Int J Obes (Lond) 34, $1149-1159$.

18. Armstrong J, Dorosty AR, Reilly JJ et al. (2003) Coexistence of social inequalities in undernutrition and obesity in preschool children: population based cross sectional study. Arch Dis Child 88, 671-675.

19. Boddy LM, Hackett AF \& Stratton G (2009) The prevalence of underweight in 9-10-year-old schoolchildren in Liverpool: 1998-2006. Public Health Nutr 12, 953-956.

20. Hogan MJ \& Strasburger VC (2008) Body image, eating disorders, and the media. Adolesc Med State Art Rev 19, 521-546, $\mathrm{x}-\mathrm{xi}$.

21. Goldschmidt AB, Aspen VP, Sinton MM et al. (2008) Disordered eating attitudes and behaviors in overweight youth. Obesity (Silver Spring) 16, 257-264.

22. Shisslak CM, Crago M, McKnight KM et al. (1998) Potential risk factors associated with weight control behaviors in elementary and middle school girls. J Psychosom Res $\mathbf{4 4}$, 301-313.

23. Yarnell JW, McCrum EE, Patterson CC et al. (2001) Prevalence and awareness of excess weight in 13 and 14 year olds in Northern Ireland using recent international guidelines. Acta Paediatr 90, 1435-1439.

24. Simon R \& Szreter S (1984) The genesis of the registrargeneral's social classification of occupations. Br J Sociol 35 , 522-546.

25. Cole TJ, Flegal KM, Nicholls D et al. (2007) Body mass index cut offs to define thinness in children and adolescents: international survey. BMJ 335, 194.

26. Cole TJ, Bellizzi MC, Flegal KM et al. (2000) Establishing a standard definition for child overweight and obesity worldwide: international survey. BMJ 320, 1240-1243.
27. Wilson EB (1927) Probable inference, the law of succession, and statistical inference. J Am Stat Assoc 22, 209-212.

28. Ogden CL, Carroll MD \& Flegal KM (2008) High body mass index for age among US children and adolescents, 2003-2006. JAMA 299, 2401-2405.

29. Mooney E, Farley H \& Strugnell C (2009) A qualitative investigation into the opinions of adolescent females regarding their body image concerns and dieting practices in the Republic of Ireland (ROI). Appetite 52, 485-491.

30. Ryan YM, Gibney MJ \& Flynn MA (1998) The pursuit of thinness: a study of Dublin schoolgirls aged 15 y. Int J Obes Relat Metab Disord 22, 485-487.

31. Fairclough SJ, Boddy LM, Hackett AF et al. (2009) Associations between children's socioeconomic status, weight status, and sex, with screen-based sedentary behaviours and sport participation. Int J Pediatr Obes 4, 299-305.

32. Johnson F, Cooke L, Croker $\mathrm{H}$ et al. (2008) Changing perceptions of weight in Great Britain: comparison of two population surveys. BMJ 337, a494.

33. Jeffery AN, Voss LD, Metcalf BS et al. (2005) Parents' awareness of overweight in themselves and their children: cross sectional study within a cohort (EarlyBird 21). BMJ 330, 23-24.

34. Wardle J \& Johnson F (2002) Weight and dieting: examining levels of weight concern in British adults. Int J Obes Relat Metab Disord 26, 1144-1149.

35. Crawford D \& Campbell K (1999) Lay definitions of ideal weight and overweight. Int J Obes Relat Metab Disord 23, 738-745.

36. Michie S (2007) Talking to primary care patients about weight: a study of GPs and practice nurses in the UK. Psychol Health Med 12, 521-525.

37. Burke V, Beilin LJ \& Dunbar D (2001) Family lifestyle and parental body mass index as predictors of body mass index in Australian children: a longitudinal study. Int J Obes Relat Metab Disord 25, 147-157.

38. Kelder SH, Perry CL, Klepp KI et al. (1994) Longitudinal tracking of adolescent smoking, physical activity, and food choice behaviors. Am J Public Health 84, 1121-1126.

39. Janz KF, Dawson JD \& Mahoney LT (2000) Tracking physical fitness and physical activity from childhood to adolescence: the muscatine study. Med Sci Sports Exerc 32, 1250-1257.

40. Reilly JJ (2006) Obesity in childhood and adolescence: evidence based clinical and public health perspectives. Postgrad Med J 82, 429-437.

41. Reilly JJ (2002) Assessment of childhood obesity: national reference data or international approach? Obes Res 10, 838-840.

42. Jebb SA \& Prentice AM (2001) Single definition of overweight and obesity should be used. BMJ 323, 999.

43. Wang Y, Monteiro C \& Popkin BM (2002) Trends of obesity and underweight in older children and adolescents in the United States, Brazil, China, and Russia. Am J Clin Nutr $\mathbf{7 5}$, 971-977.

44. Chinn S \& Rona RJ (2001) Prevalence and trends in overweight and obesity in three cross sectional studies of British Children, 1974-94. BMJ 322, 24-26.

45. Hawkins SS, Griffiths LJ, Cole TJ et al. (2008) Regional differences in overweight: an effect of people or place? Arch Dis Child 93, 407-413. 